\title{
Erinnerungskultur in Pfarrkirchen Hedwig von Dänemark (1581-1641), die Familie von Kanne und die Kirche zu Gentha
}

\author{
von \\ UTE ESSEGERN
}

Zufallsfunde gibt es immer wieder. Im Herbst 2011 entlockten Restauratoren einem Cranach-Altar in der Zwickauer Annenkirche ein Geheimnis. Unter der Farbschicht verborgen fanden sie ein Gesicht, welches Cranach letztendlich verworfen hatte. ${ }^{1}$ Weniger publik, jedoch nicht minder interessant ist ein ,verstecktes' Porträt, welches eine Frau als Jüngerin am Tisch zusammen mit elf Aposteln und Jesus zeigt und ebenfalls im Herbst 2011 auf einem Altargemälde gefunden wurde. Dieses steht im Mittelpunkt des folgenden Beitrags.

Mitten im alten Wittenberger Kurkreis, fünf Kilometer von Seyda und gut 20 Kilometer von Wittenberg entfernt, liegt das kleine Dorf Gentha. 1385 erstmals urkundlich erwähnt, wurde das Dorf 1611 als Teil des Leibgedinges an die verwitwete sächsische Kurfürstin Hedwig, einer geborenen Prinzessin aus Dänemark, übergeben. ${ }^{2}$ Hedwig ließ hier um 1624 eine Kirche (vgl. Abb. 1) erbauen. ${ }^{3}$ Im Dreißigjährigen Krieg und gut

1 Vgl. Sächsische Zeitung. Ausgabe Dresden, 16. Dezember 2011, S. 6, Bildnachricht „Cranach-Altar birgt ein Geheimnis“.

2 Hedwig von Dänemark (1581-1641) hatte 1602 den sächsischen Kurfürsten Christian II. (1583-1611) geheiratet. Nachdem ihr Mann am 23. Juni 1611 unerwartet mit erst 27 Jahren kinderlos verstorben war, zog Hedwig noch im selben Jahr in das bei Prettin gelegene Schloss Lichtenburg. Dieses hatte sie sich als Witwensitz selbst ausgesucht. Zu ihrem Leibgedinge zählten die Ämter Schlieben, Schweinitz und Seyda. Gentha gehörte zum Amt Seyda. Zum Leben und Wirken Hedwigs vgl. UTE EssEgERN, Fürstinnen am kursächsischen Hof. Lebenskonzepte und Lebensläufe zwischen Familie, Hof und Politik in der ersten Hälfte des 17. Jahrhunderts (Schriften zur sächsischen Geschichte und Volkskunde 19), Leipzig 2007; sowie JutTA Kappel/Claudia BrinK (Hg.), Mit Fortuna übers Meer. Sachsen und Dänemark, Ehen und Allianzen im Spiegel der Kunst (1548-1709), Berlin 2010, mit weiteren Literaturhinweisen. Zu Hedwigs Wirken als Kirchenpatronin in ihrem Leibgedinge vgl. auch Abschnitt III dieses Beitrags. Zur den rechtlichen und finanziellen Rahmenbedingungen der Witwenschaft vgl. auch UTE ESSEGERN, Kursächsische Eheverträge in der ersten Hälfte des 17. Jahrhunderts, in: Martina Schattkowsky (Hg.), Witwenschaft in der Frühen Neuzeit. Fürstliche und adlige Witwen zwischen Fremd- und Selbstbestimmung (Schriften zur sächsischen Landesgeschichte 6), Leipzig 2003, S. 115-135.

3 Möglicherweise gab es einen Vorgängerbau, denn zur Kirche gehört auch ein zweiter romanischer Taufstein, der erst im Jahr 2000 vor der Kirche entdeckt wurde. Allerdings setzt die überlieferte Kirchenchronik erst mit dem Neubau ein. Zum Neubau durch Hedwig vgl. CONRAD BARTHEls, Christlicher Leich-Sermon/Von Der ... Frawen Hedwig/ Gebornen aus Königlichem Stam[m]e Dennemarcken/Hertzogin zu Sachsen ..., Torgau 1642, in: Verzeichnis der Drucke des 17. Jahrhunderts (im Folgenden: VD 17), (VD 17 14:009466C), Bl. 42. Vgl. auch „Zur Chronik der Genthaer Kirche“ [Manuskript der Kirchgemeinde Gentha], dabei handelt es sich um eine zwischen 1878 und 1891 durch Pastor Elschner entstandene Abschrift einer Chronik aus einem heute nicht mehr existierenden Gebetsbuch. Urheber der bis 1724 getätigten Einträge ist Johannes Donath, der seit 1700 als 
ein Jahrhundert später im Siebenjährigen Krieg wurde die Kirche stark beschädigt, jedoch immer wieder in Fachwerkbauweise aufgebaut. ${ }^{4}$ Das bereits erwähnte Altargemälde (vgl. Abb. 2) im Inneren der Kirche ist Teil eines geschlossenen Kanzelensembles, welches in seiner Einfassung die Zahlen 3 und 8 sowie die Buchstaben $\mathrm{C}$ und $\mathrm{H}$ aufgreift und das dänische Wappen zeigt. Sowohl Zahlen und Buchstaben als auch das Wappen weisen auf die Stifterin der Kirche, Hedwig von Dänemark, hin. ${ }^{5}$

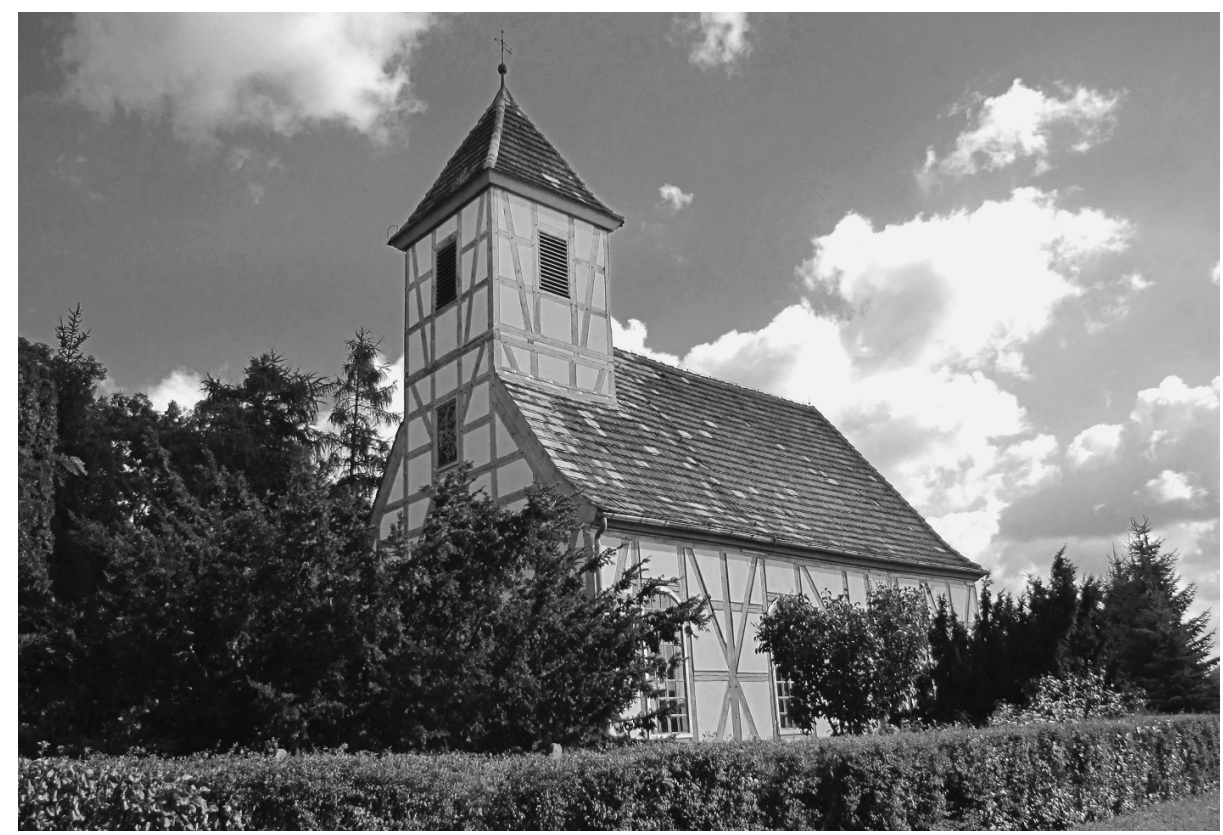

Abb. 1: Außenansicht der Kirche von Gentha. Foto: Ute Essegern.

Schulmeister in Gentha wirkte. Alle Ereignisse vor 1700 kannte Donath folglich nur aus zweiter oder dritter Hand. Zu Hedwigs Wirken als Kirchenpatronin vgl. auch Kapitel III dieses Beitrags.

4 Vgl. Zur Chronik der Genthaer Kirche (wie Anm. 3). Vgl. dazu auch Sächsisches Staatsarchiv - Hauptstaatsarchiv Dresden (im Folgenden: HStA Dresden), 10036 Finanzarchiv, Rep. A 25 a II, IV B, Nr. 2885: Begnadungsverschreibung über das wüste Dorf Gentha im Amt Seyda an Bernhard Ludolph Kannen zu Klöden 1652, Bl. 4 f., Bericht aus Lichtenburg über Gentha, um 1651. Darin wird erwähnt, das Dorf sei 1637 zerstört worden, die Kirche würde aber noch stehen. Allerdings habe der Kurfürst veranlasst, dass das Inventar nach Jessen gebracht wurde. Zur Zerstörung im Siebenjährigen Krieg vgl. Heimatglocken. Gemeindeblatt für das Kirchspiel Elster an der Elbe, Ausgabe Juli 1925, Artikel über die Kirche Gentha. Darin wird auf Akten des Pfarrarchivs von Elster verwiesen, welche die Kollekten zum Bau der Kirche von Gentha dokumentieren - jedoch ohne Jahreszahl. Der Autor ist sich aber anhand der Handschrift sicher, dass die Kollekte während der Zeit eines Pastors Schmidt erfolgte, der von 1752 bis 1786 das Pfarramt zu Elster verwaltete. Dies kann so nicht nachvollzogen werden, da die gesammelten 13 Taler, 23 Groschen und 27 Pfennig eher auf eine Sanierung als auf einen Neubau der Kirche hinweisen.

5 Die Zahlen 3/8 stehen als Zahlenrebus für die Buchstaben $\mathrm{C} / \mathrm{H}$. Aufgelöst können sie sich sowohl auf Hedwig allein (Churfürstin/Hedwig) als auch auf sie und ihren Ehemann gemeinsam (Christian/Hedwig) beziehen. Für Hedwig sind die Buchstaben und Zahlen 


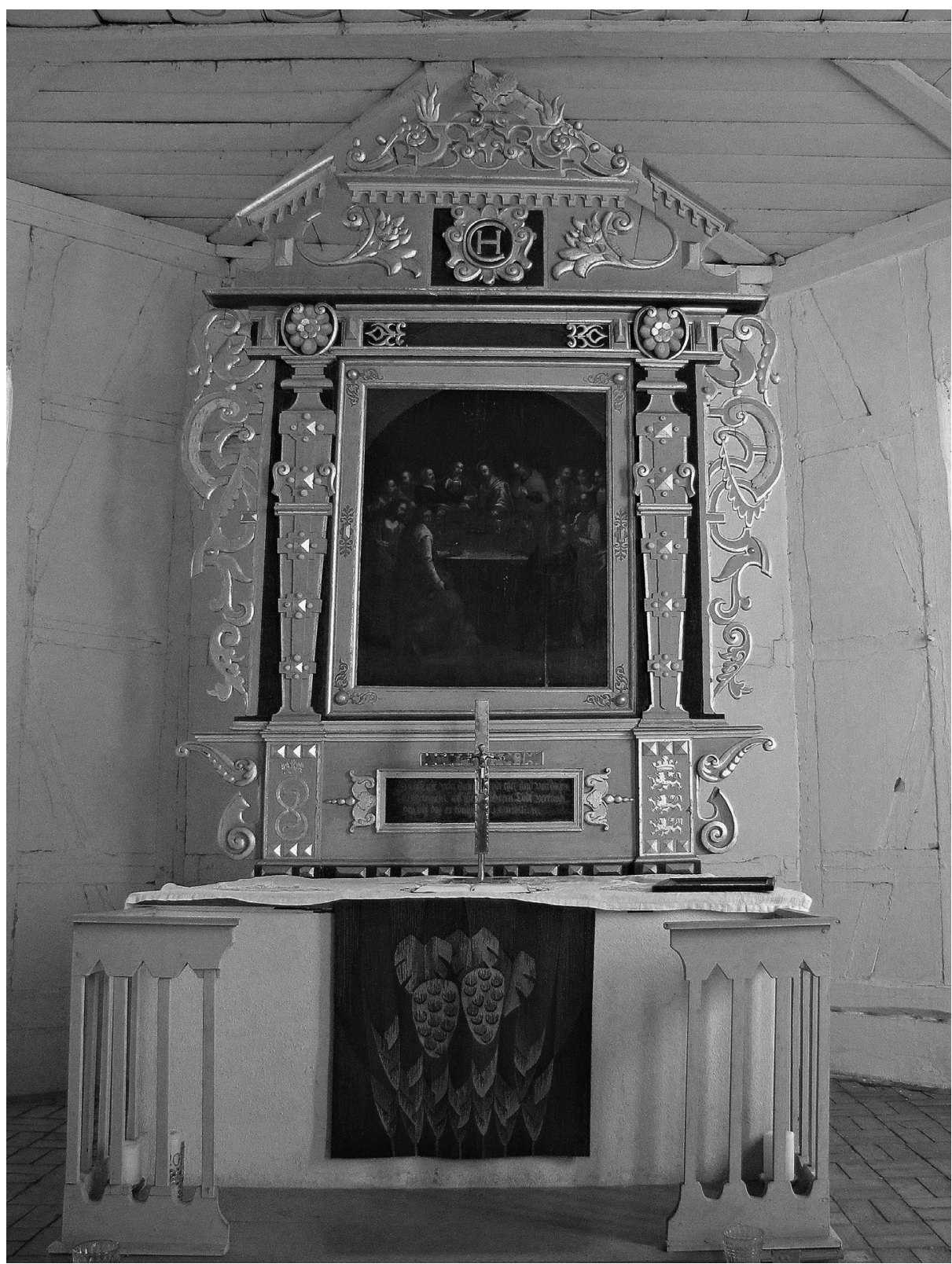

Abb. 2: Altar in der Kirche von Gentha. Foto: Ute Essegern.

häufig nachweisbar. Vgl. KAPpel/BRINK, Mit Fortuna übers Meer (wie Anm. 2), S. 156 f. Zur Auflösung der Buchstaben vgl. auch Anm. 41. Dort sogar als Ligatur HC, welche eher auf Hedwig Churfürstin hindeutet. 
Die angesprochene Altareinfassung legte anfangs die Vermutung nahe, dass auch der Altar eine Stiftung Hedwigs sein könnte. Eine nach 1700 angefertigte Chronik der Pfarrkirche erwähnt jedoch eindeutig einen anderen Auftraggeber: Anno 1695 ist die Kirche zu Gentha renoviret und die Decke und Stüble von dem Woblgeborenen Freulein Johanne Elisabeth von Kannen schön blau mit Wolken gemalet worden. Anno 1695 ist der hobe Alter in der Kirche albier mit der Kanzel gemalt, derin die Abbildung der Einsetzung des Heil. Nachtmables des Herrn Jesu mit den 12 Aposteln wie auch der Churfürstin Hedwig Name mit C. H. und Königl. Denemarklichen Wappen gemablet, so die Frälin Johanne Elisabeth von Kannen an $50 \mathrm{rt}$. darzu angewendet hat. ${ }^{6}$ Interessant ist diese Chronik nicht nur in Hinblick auf die Urheberschaft. Deutlich wird zudem, dass der seit 1700 in Gentha lebende Autor des Eintrages die Abbildung einer Frau als Apostel auf dem Gemälde als nicht sonderlich erwähnenswert fand.

Könnte diese Frau die sächsische Kurfürstenwitwe Hedwig sein? Versteckte Porträts, sogenannte Kryptoporträts, sind in biblischen, mythologischen oder allegorischen Gemälden des Spätmittelalters und der Frühen Neuzeit keine Seltenheit. ${ }^{7}$ Die Auftraggeber nutzten diese Form der zumeist eigenen Darstellung als Bekenntnis zur Identifikation mit dem dargestellten Charakter. Sie strebten nicht selten einen Vergleich mit der Frömmigkeit oder Tugend ihrer Vorbilder an, wählten dies als eine Form der Huldigung oder gaben es als Zeichen der Ehrerbietung in Auftrag. Sie waren aber nicht selten auch Ausdruck eines neuen Selbstbewusstseins. Die Schwierigkeit besteht heute darin, einen exakten Nachweis über die Identität der, versteckten' Person zu bringen. ${ }^{8}$

6 Zur Chronik der Genthaer Kirche (wie Anm. 3).

7 Vgl. dazu und zu den folgenden Ausführungen Friedrich B. Polleross, Die Anfänge des Identifikationsporträts im höfischen und städtischen Bereich, in: FrühneuzeitInfo 4 (1993), H. 1, S. 17-36, besonders S. 27; zur ausführlichen Typologie vgl. vor allem S. 17. Vgl. auch GERHART LADNER, Die Anfänge des Kryptoporträts, in: Lorenz Deuchler/ Mechthild Flury-Lemberg/Karel Otavsky (Hg.), Von Angesicht zu Angesicht. Porträtstudien. Michael Stettler zum 70. Geburtstag, Bern 1983, S. 78-97. Andere Begriffe dafür sind Identifikationsporträts, Inkognitoporträts oder Portrait historie. Die Forschung geht heute davon aus, dass es viel mehr solcher Kryptoporträts gibt als bisher nachgewiesen.

8 Einfach ist es, wenn es sich um bekannte Personen handelt, wie beispielsweise um die Fürsten von Anhalt (Vgl. PETER FindeISEN, Bildnisse der Fürsten Wolfgang und Joachim von Anhalt in Zerbst, Dessau und Köthen, in: „Es Thvn Ihrer Viel Frage ...“. Kunstgeschichte in Mitteldeutschland, Petersberg 2001, S. 171-186) oder in dem von Lucas Cranach d. Ä. (1472-1553) geschaffenen Reformationsaltar in der Wittenberger Stadtkirche, welcher u. a. Martin Luther als Jünger beim Abendmahl, aber auch andere versteckte Porträts zeigt. Vgl. Albrecht Steinwachs/Jürgen M. Pietsch, Der Reformationsaltar. Lucas Cranach der Ältere, Lucas Cranach der Jüngere - Stadtkirche St. Marien, Lutherstadt Wittenberg, Spröda 2011. Auch Herzog Kasimir VI. von Pommern (1557-1605) ließ sich vermutlich als Jünger in einem Abendmahlgemälde verewigen, vgl. dazu aktuell RALFGunNar Werlich, Verschollene Quellen zur Camminer Bistumsgeschichte aus Bast und Cammin in alten Fotografien, in: Pommern. Zeitschrift für Kultur und Geschichte 2012, H. 2, S. 4-7. Bekannt sind ebenfalls die Darstellungen der Judith bei Lucas Cranach, welche in der Kleidung hochadliger Frauen erscheint und so eine „Projektions- und Identifikationsfigur für protestantische Fürstinnen“ darstellt. Vgl. Tagungsbericht: LENA OETZEL, Fürstinnen und Konfession. Beiträge hochadliger Frauen zur Religionspolitik und Konfessionsbildung, 24. bis 26. März 2011 in Gotha, in: H-Soz-u-Kult, 21. Mai 2011; http:// hsozkult.geschichte.hu-berlin.de/tagungsberichte/id=3659 (Zugriff 22. Januar 2012). 


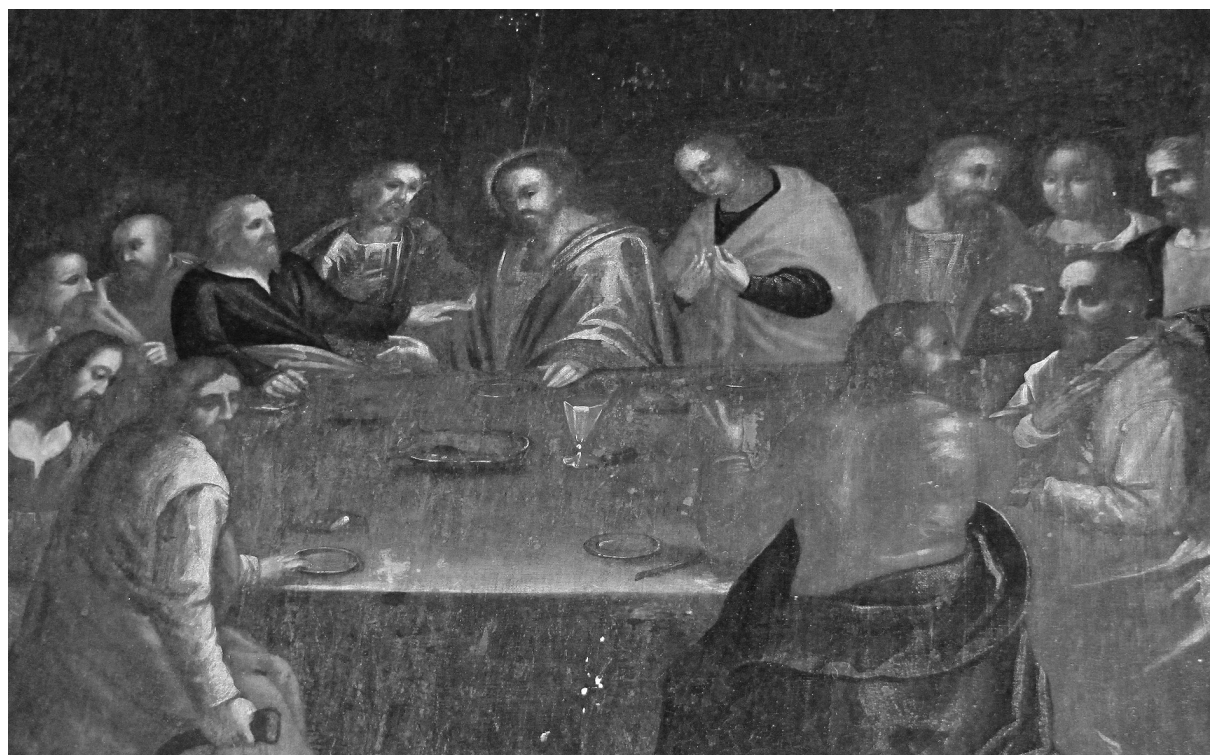

Abb. 3: Altarbild. Foto: Ute Essegern.

Das Genthaer Gemälde zeigt das Letzte Abendmahl. Jesus in der Mitte am Tisch sitzend wird von je sechs Jüngern zu beiden Seiten flankiert (vgl. Abb. 3). Die Gesichter der Jünger und auch Jesu sind gleichförmig gemalt. Den Blick nach unten gerichtet, sind die Köpfe eher länglich geformt. Stereotyp tragen sie - bis auf zwei lange Bärte. Eindeutig identifizierbar ist im Vordergrund anhand des Geldbeutels Judas. Die direkt rechts neben Jesus sitzende Person sowie die zweite von rechts sind ohne Bart und eher androgyn - letztere noch mehr als die erste. Rechts neben Jesus könnte, dem typischen Bildaufbau für Abendmahldarstellungen folgend, möglicherweise Johannes abgebildet sein. Bei der anderen Figur (vgl. Abb. 4) sind nicht nur die weiblichen Merkmale wesentlich deutlicher ausgeprägt als bei dem mutmaßlichen Johannes, sondern sie blickt auch, mehr noch als die Judasfigur im Vordergrund, aus dem Bild heraus. Ein Gemälde der Staatlichen Kunstsammlungen Dresden, welches die sächsische Kurfürstin Hedwig zeigt (vgl. Abb. 5), hat eine gewisse Ähnlichkeit mit der in Abb. 4 gezeigten Person, auch wenn vielleicht beide Porträts sehr stark typisiert sind. ${ }^{9}$

9 Prof. Matthias Müller, Professur für Kunstgeschichte mit Schwerpunkten im Mittelalter und in der beginnenden Frühen Neuzeit an der Johannes Gutenberg-Universität Mainz, Institut für Kunstgeschichte, hält das Vergleichsbild Hedwigs für eine eindeutige Identifizierung allein als nicht ausreichend, „da die Typisierung sowohl des Porträts als auch der Stifterfigur so weit getrieben ist, dass individuelle Züge kaum festgestellt werden können." (Mail vom 2. Februar 2012). So käme auch die Altarstifterin Johanna Elisabeth von Kanne als Abgebildete in Betracht. Allerdings deuten Wappen und Symbole am Rahmen natürlich eher auf Hedwig hin. 


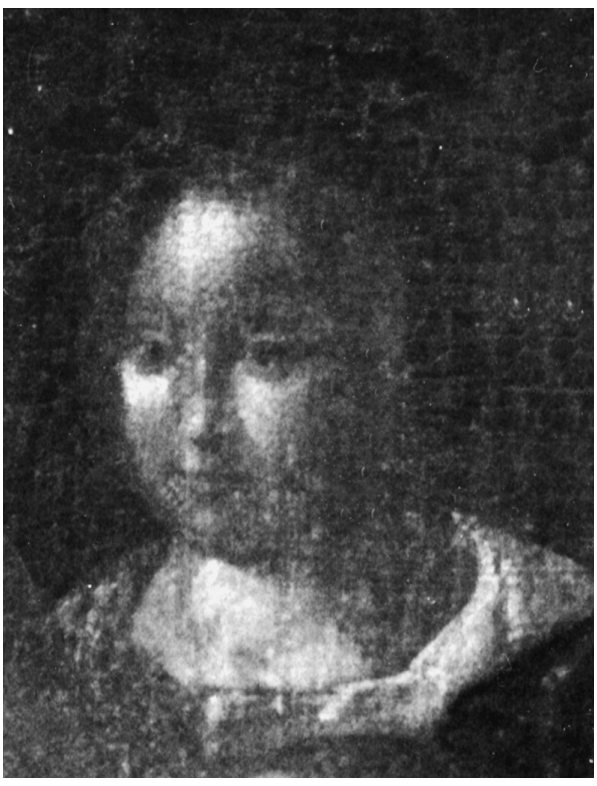

Abb. 4:

Detail des Altarbildes. Foto: Dietmar Steinecker.

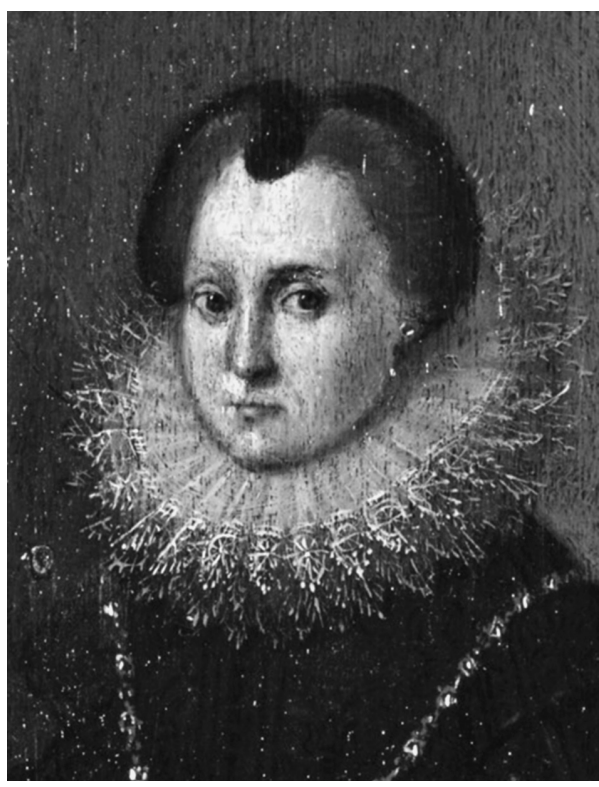

Abb. 5:

Hedwig von Dänemark, unbekannter Meister, nach 1611. Staatliche Kunstsammlungen Dresden, Rüstkammer, H 181.

Auf dem Vergleichsbild (Abb. 5) ist die Gesichtsform zwar etwas länglicher dargestellt als auf dem Altarbild (Abb. 4), doch stimmen Stirn-, Augen-, Nasen- und Kinnpartie überein. Nur erahnen lässt sich, dass die Frau auf dem Altarbild vielleicht mit einer schwarzen Haube einen ähnlichen Kopfschmuck wie Hedwig zu tragen scheint. Folgt man allen bisher bekannten Hinweisen, so liegt die Vermutung nahe, dass der Maler in dem Genthaer Abendmahl tatsächlich Hedwig als Jüngerin an der Seite Jesu und seiner Apostel dargestellt und damit ein Kryptoporträt geschaffen hat. Es ist durchaus denkbar, dass als Vorlage vielleicht dieses hier beschriebene oder ein anderes Gemälde des gleichen Malers diente, welches sich vielleicht in Besitz der Familie von Kanne befand. ${ }^{10}$ Im Folgenden wird der Frage nachgegangen, wie das Gemälde in die Kirche kam und warum Hedwig darauf so prominent in Szene gesetzt worden sein könnte.

10 Hedwig hatte an ihrem Witwenhof in Lichtenburg einen eigenen Maler namens Johann Frauenstein, der vor allem Porträts anfertigte. Diese wurden an andere Fürstenhöfe geschickt, aber gerne auch als Miniaturen verschenkt. Vgl. EsSEGERN, Fürstinnen am kursächsischen Hof (wie Anm. 2), S. 135. Kleine Miniaturbilder wurden an den Höfen jener Zeit oft in Form von Medaillons oder Miniaturbildern zum neuen Jahr oder ähnlichen Anlässen verteilt. Leider gibt es aktuell keinen Nachweis, ob die Familie von Kanne ein Porträt Hedwigs besaß. Aufgrund der persönlichen Nähe (vgl. den folgenden Abschnitt des Beitrages) zu Hedwig ist dies jedoch wahrscheinlich. 


\section{Gentha, Hedwig von Dänemark und die Rittergutsbesitzer von Kanne}

Als die kursächsische Witwe Hedwig zwischen 1611 und 1641 in Lichtenburg residierte, verwaltete sie die ihr überlassenen Ämter Schlieben, Schweinitz und Seyda selbst und führte dank einer ausgesprochen guten finanziellen Absicherung ein für hochadlige Witwen unabhängiges Leben. ${ }^{11}$ Gentha gehörte zum Amt Seyda. Um 1624 wurde die Genthaer Kirche im Fachwerkstil erbaut. Dass Hedwig von Dänemark tatsächlich die Stifterin der Kirche ist, belegen sowohl ihre Leichenpredigt als auch der Eintrag in der Kirchenchronik von Gentha. Zudem hatte Hedwig in den ehevertraglichen Regelungen für den Witwenfall auch das Patronatsrecht über ihre Wittumskirchen und damit über die von ihr errichtete Kirche von Gentha erhalten. ${ }^{12}$

Als das Dorf mitten im Dreißigjährigen Krieg um 1637 niedergebrannt wurde, erlitt auch die Kirche starke Schäden. Gegen Ende des Krieges war das Dorf wüst, es lebten dort kaum mehr als eine Handvoll Menschen, ein Wiederaufbau erschien undenkbar. ${ }^{13}$ Dass das Dorf und damit auch die Kirche gerettet wurden, ist einem der engsten Vertrauten Hedwigs zu verdanken: Dem ursprünglich aus Westfalen stammenden Bernhard Ludolph von Kanne, Rittergutsbesitzer auf Klöden. ${ }^{14}$ Kanne hatte sich 1651 vom sächsischen Kurfürsten das wüste Dorf Gentha als Rittergut auserbeten. ${ }^{15}$ Aus den Akten geht leider nicht hervor, warum er sich ausgerechnet ein wüstes Dorf ausgesucht hat. Mit der Belehnung erhielt er zugleich das Patronatsrecht für die Kirche. Nach

11 Vgl. Essegern, Kursächsische Eheverträge (wie Anm. 2), sowie DiEs., Fürstinnen am kursächsischen Hof (wie Anm. 2), S. 49-220, besonders S. 63-66. Hedwigs Witwenzeit fiel jedoch auch in die Zeit des Dreißigjährigen Krieges. Mitteldeutschland war nicht durchgängig, doch immer wieder Zentrum des Kriegsgeschehens. Zu den sächsischen Ereignissen vgl. u. a. Christian LeHMAnN, Die Kriegschronik. Sachsen mit Erzgebirge, Reprint Scheibenberg 1998. Auch die Wittumsämter Hedwigs waren davon betroffen, doch Dank Hedwigs Anwesenheit nicht so stark wie andere Regionen. Vgl. dazu EsSEgERN, Fürstinnen am kursächsischen Hof (wie Anm. 2), vor allem S. 152-182.

$12 \mathrm{Zu}$ den ehevertraglichen Regelungen vgl. EsSEGERN, Fürstinnen am kursächsischen Hof (wie Anm. 2), S. 63-66 und 73-76; DiEs., Kursächsische Eheverträge (wie Anm. 2); sowie HStA Dresden, 10001 Ältere Urkunden, Nr. 12577 (Ehevertrag von 1602), Nr. 125791-12598 (Zusatzverträge), vor allem Nr. 12594 (Leibgedingebrief).

13 Vgl. dazu HStA Dresden, 10036 Finanzarchiv, Rep. A 25 a II, IV B, Nr. 2885, Bl. 4 f. (wie Anm. 4).

14 Vgl. Abraham Calov, Verae Nobilitatis Insignia... / ... Bey ... Leichbegängnüs Des ... Bernhard Ludolph Kanne..., Wittenberg 1660 (VD 17 39:111001Z). Der Leichenpredigt folgend wurde Kanne am 24. August 1588 in Westfalen geboren und starb am 19. März 1660 auf Klöden. Er kam schon in seiner Kindheit nach Sachsen. Seine Frau Elisabeth von Wulff, Tochter des Carl von Wulff, stammte ebenfalls aus Westfalen. Zum Verhältnis von Hedwig zu Kanne schreibt Calov, Hedwig habe Kanne lieb und wert gehalten, ihn auch auf Klöden besucht. Vgl. auch EsSEGERN, Fürstinnen am kursächsischen Hof (wie Anm. 2), S. 518 mit weiteren Nachweisen. Der Familiennachlass der von Kanne befindet sich heute im Archiv Breitenhaupt, welches im Westfälischen Archivamt aufbewahrt wird. Dort sind auch die Korrekturfahnen des folgenden Buches überliefert: WERNER KONSTANTIN ARNSWALDT, Geschichte der Familie von Kanne, 1935. Der Abschnitt 5 beschäftigt sich ab S. 340 mit dem sächsischen Zweig der Linie. Hier vor allem S. 353 f.

15 Vgl. HStA Dresden, 10036 Finanzarchiv, Rep. A 25 a II, IV B, Nr. 2885, (wie Anm. 4), Bl. 1, Johann Georg I. von Sachsen bewilligt Bernhard Ludolph von Kanne am 6. Mai 1651 in Lichtenburg das wüste Dorf Gentha. Bl. 6-9 ist der Entwurf oder die Abschrift des Begnadigungsschreibens auf das wüste Dorf Gentha vom 30. Juni 1652. Die Lehnakten selbst sind im Landeshauptarchiv Sachsen-Anhalt - Standort Wernigerode überliefert. 
1652 ließ er Dorf und Kirche schrittweise wieder aufbauen. Als er 1660 starb, erbten seine Söhne das Rittergut, wobei der 1617 geborene Christian Ernst das Familienoberhaupt war. ${ }^{16}$ Christian Ernst verkaufte das Rittergut Gentha um 1673 seinem jüngeren, 1628 geborenen Bruder Raban, der es in ein Mann- und Weiberlehen umwandeln ließ. Raban war mit der 1644 geborenen Clara Catharina von Hacke verheiratet. ${ }^{17}$ Gemeinsam hatten sie vier Kinder: Johanna (Anna) Elisabeth (später mit Gottfried Moritz von Bolberitz verheiratet und 1729 in der Oberlausitz verstorben), Hedwig Magdalena, Ludolph Wilhelm (Wilke) und Anna Dorothea (verheiratete Vittinghof). ${ }^{18}$ Nach dem Tod Rabans erbte 1674 erst sein einziger Sohn Gentha. Nach dessen Tod 1687 wurden die drei Töchter 1692 und im Mai 1695 mit Anteilen des Gutes belehnt. Rabans Witwe Clara Catharina heiratete einen Obristen von Kuffer (Kupfer), blieb aber in Vormundschaft ihrer Kinder zugleich Erb-, Lehn- und Gerichtsfrau von Gentha. Als solche wird sie 1689 und 1692 in der Kirchenchronik erwähnt. Die drei Töchter verkauften 1695 Gentha an ihre in Dresden lebende Mutter. Trotzdem stiftete Johanna Elisabeth im gleichen Jahr nicht nur den Altar, sondern ließ die Kirche auch renovieren. ${ }^{19}$ Das

16 Vgl. ebd., Bl. 11, Christian Ernst, Raban und Moritz Siegfried von Kanne an Kurfürst Johann Georg II., Dresden, den 20. September 1668. Darin erwähnen sie, dass es nach dem Tod des Vaters noch keine Erbsonderung unter den Brüdern gegeben habe und bitten trotzdem um die Erneuerung des Lehnbriefes. Bl. 12-14 Erneuerung des Lehnbriefes durch Johann Georg II. an die drei Brüder, Dresden, den 14. September 1668. Bernhard Ludolph von Kanne hatte sechs Söhne und eine Tochter. Der Erstgeborene Bernhard Ludolph (1614) starb 1638 im Kriegsdienst. 1617 folgte Christian Ernst. Der 1618 geborene Wolf Dietrich fiel ebenfalls im Krieg. Der 1620 geborene Sohn Hans Georg und die 1626 geborene Tochter Hedwig Elisabeth starben 1637 an der Pest. 1628 wurde Raban geboren, 1635 Moritz. Raban und Moritz standen 1660 in schwedischen Militärdiensten. Vgl. dazu BARTHELS, Christlicher Leich-Sermon (wie Anm. 3). Die weitere Erbfolge in Gentha nach dem Tod Bernhard Ludolph von Kannes hat freundlicherweise Dr. Jörg Brückner vom Landeshauptarchiv Sachsen-Anhalt - Standort Wernigerode auf Basis der dort überlieferten Lehn- und Hypothekenakten ermittelt. Zu Christian Ernst vgl. auch die Leichenpredigt von MARTIN GEIER, Himlische Zusammenkunft. wie sie ... bei ... Leichbestattung. Des ... Hn. Christian Ernst/ Freiherrn von Kannen ... ingesencket worden, Dresden 1677 (VD 17 14:014187P). Er hinterließ seiner Witwe Charlotte von Lützelburg nur zwei Töchter: Elisabeth Charlotte und Louyse Marie. Vgl. auch ARNSWALDT, Geschichte (wie Anm. 14), S. 361.

17 Vgl. http://www.geneall.net/D/per_page.php?id=1911641, Datenblatt zur Familie des Bernhard Ludolph von Kanne (Zugriff 28. Dezember 2011). Im Amt Schlieben war 1627 ein Ehrenreich Hacke in Pettkus als schriftsässiger Adliger geführt. Vgl. HStA Dresden, 10036 Finanzarchiv, ehem. Magd. Rep. A 25 a I, Anhang, Lit. XL, Steuersachen, Nr. 3, Kurkreis betr. 1626/27. Möglicherweise stammte Clara Catharina aus dieser Linie und damit ebenfalls aus den Wittumsämtern der verstorbenen Kurfürstin Hedwig.

18 Vgl. http://www.geneall.net/D/per_page.php?id=1911651, Datenblatt zur Familie Raban von Kannes sowie mit weiteren Verlinkungen auf Anna Elisabeth (Zugriff 28. Dezember 2011), sowie die Hinweise von Dr. Jörg Brückner (wie Anm. 16).

19 Vgl. Zur Chronik der Genthaer Kirche (wie Anm. 3). Ob der folgende, bei ARnsWALDT, Geschichte (wie Anm. 14), S. 376 f. erwähnte Fakt vielleicht ein Auslöser der Stiftung gewesen sein könnte, bleibt Spekulation. 1695 war eine Tochter Christian Ernst von Kannes (Elisabeth Charlotte, verheiratete von Arnim) verhaftet worden. Sie wurde verdächtigt, am Tod des 1694 verstorbenen sächsischen Kurfürsten Johann Georg IV. (16681694) mitschuldig gewesen zu sein. Dieser war wenige Tage nach seiner Geliebten Magdalena Sibylla von Neitschütz (1675-1694) verstorben. Dessen Bruder, der neue Kurfürst Friedrich August I. (1670-1733), beschuldigte daraufhin die Mutter der verstorbenen Geliebten, Ursula Margaretha von Neitschütz (1650-1713), der Hexerei. Die Angeklagte 
Gut blieb bis 1702 im Besitz von Rabans Witwe, ehe diese es an die Familie von Brandenstein veräußerte. ${ }^{20}$

Doch zurück zu den Kannes. Warum auch 54 Jahre nach dem Tod Hedwigs die Erinnerung an sie in Gentha so lebendig geblieben ist, lässt sich in vielen Teilen nur vermuten. Eine wichtige Rolle spielte sicherlich Hedwigs enges Verhältnis zur Familie von Kanne, aber auch Hedwigs Wirken als Patronin ihrer Wittumskirchen.

\section{Hedwig und die Familie von Kanne}

Als Hedwig 1611 ihren Witwensitz bezog, konnte sie Ritterdienste von den in ihren Ämtern ansässigen Rittergutsbesitzern in Anspruch nehmen. Dies bedeutete, dass die Rittergutsbesitzer ihr bei Bedarf am Witwenhof aufzuwarten hatten, sie aber auch auf Reisen mit eigenen Pferden begleiten mussten. Der Rittergutsbesitzer Bernhard Ludolph von Kanne und seine Frau Elisabeth waren, ebenso wie Hedwig, ,neu' im Kurkreis. ${ }^{21}$ Gut möglich, dass dies ein Punkt war, warum Hedwig ausgerechnet zu den auf Klöden lebenden Kannes ein engeres Verhältnis als zu anderen Rittergutsbesitzern ihrer Wittumsämter aufbaute. In den ersten Jahren von Hedwigs Witwenschaft begleitete Kanne die junge Witwe oft auf deren Reisen. ${ }^{22} 1620$ wechselte er jedoch an den kurfürstlichen Hof nach Dresden, wo er bis 1626 als Kammerjunker diente. Dann bat er um seinen Abschied, um wieder auf Klöden bei seiner Familie leben zu können. Seine Frau hatte in Klöden gerade das fünfte Kind entbunden. ${ }^{23}$ Im Auftrag des Kurfürsten begleitete er Hedwig, aber auch andere kurfürstliche Personen weiterhin auf deren Reisen. So war er 1632 vermutlich auch in Dänemark, als Kurfürst Johann

war eine Verwandte Elisabeth Charlotte von Kannes mütterlicherseits. Elisabeth Charlotte wurde im Januar 1695 verhaftet und im April freigesprochen. Andererseits zahlte ihre Familie im Juli 1695 noch eine Kaution von 3.000 Talern. Trotzdem befand sie sich Ende des Jahres immer noch in Haft und wurde erst im Laufe des Jahres 1696 entlassen. Es ist zu vermuten, dass die Kannes mit der Altarstiftung ihre Verbundenheit zum kursächsischen Herrscherhaus demonstrieren wollten. Vielleicht hatten sie Angst, nach der Verhaftung ihrer Verwandten ebenfalls in das Blickfeld der Ermittler zu gelangen. Beweise dafür gibt es aber nicht.

20 Auch in den folgenden Jahren diente es weiter als „Weiberlehen“. Vgl. Zur Chronik der Genthaer Kirche (wie Anm. 3). 1716 war Maria Salome von Brandenstein die Erb-, Lehn- und Gerichtsfrau Genthas. Vermutlich ging der Besitz an deren Tochter oder Verwandte Johanna Sibylla von Brandenstein über, die möglicherweise Kontakte zum Hof der sächsischen Kurfürstin Christiane Eberhardine (1671-1727) in Pretzsch hatte. Ein Indiz dafür ist, dass 1721 Christiane Eberhardine der Kirche in Gentha zehn Taler für Reparaturen stiftete und drei Jahre später Johanna Sibylla von Brandenstein der Kirche ein Kruzifix für den Altar übergab. Die Brandenstein beschenkte die Kirche als verheiratete Frau von Polenz 1753 erneut.

21 Zur Herkunft der Kannes vgl. Anm. 14.

22 Vgl. z. B. HStA Dresden, 10024 Geheimes Archiv, Loc. 8220/2, Herzog Augusti zu Sachsen-Weißenfels Geburt und bei dessen christlicher Taufe gewesene fremder Herrschaften erfolgte Gratulation-Schriften, auch gehaltene Ritterspiel und Armbrustschießen, 1614. Darin der Fourierzettel Hedwigs, Bl. 125; auch ebd., Loc. 10735/26, Wie Kaiser Matthias nebst der königlichen Würden in Böhmen und Erzherzog Maximilians zu Österreich Kurfürst Johann Georg [I.] zu Sachsen in Dresden besucht, 1617, Bl. 14.

23 Vgl. Calov, Verae Nobilitatis Insignia (wie Anm. 14) sowie das Datenblatt zur Familie Bernhard Ludolph von Kannes auf http://www.geneall.net/D/per_page.php?id= 1911641 (Zugriff 28. Dezember 2011). 
Georgs I. von Sachsen (1585-1656) jüngste Tochter Magdalena Sibylla (1617-1668) dem dänischen Erbprinzen Christian (V.) (1603-1647) zur Frau gegeben wurde. Nicht nur zu Hedwig hatte Kanne gute Kontakte. Der mecklenburgische Herzog Adolf Friedrich I. (1588-1658) weilte vom 4. bis zum 8. Juni 1629 auf Klöden. ${ }^{24}$ Auch die sächsischen Herzöge August (1614-1680) und Christian (1615-1691) besuchten Kanne auf seinem Gut. ${ }^{25}$ Bernhard Ludolph von Kanne wurde später als Kriegskommissar in Wittenberg geführt und war als solcher für den Kurkreis verantwortlich. ${ }^{26}$

Seine Frau Elisabeth hielt sich oft am Lichtenburger Hof auf, obwohl sie selbst kleine Kinder hatte. Ohne konkrete Funktion geführt, hat sie sich besonders um die bei Hedwig lebenden mecklenburgischen Herzogskinder Anna Maria (1627-1669) und Johann Georg (1629-1675) gekümmert. So berichtete sie dem mecklenburgischen Herzogspaar von deren Leben am Lichtenburger Hof. ${ }^{27}$ Nach dem Tod Hedwigs blieb Elisabeth der mecklenburgischen Prinzessin Anna Maria verbunden, welche 1647 den sächsischen Prinzen August (ab 1657 Herzog von Sachsen-Weißenfels) heiratete und in Halle lebte. ${ }^{28}$ Elisabeth von Kannes ältere Söhne kämpften und starben während des Dreißigjährigen Krieges auf sächsischer Seite, die zwei Jüngsten standen nach dem Krieg in schwedischen und sächsischen Militärdiensten. Der 1617 geborene Christian Ernst hatte ab 1626 als Page an Hedwigs Witwenhof und später bei Hedwigs Neffen Herzog Ulrich von Dänemark (1611-1633) sowie bei ihrem Bruder, König Christian IV. von Dänemark (1577-1648), gedient. ${ }^{29}$ Interessant ist auch, dass Hedwigs letzter Hofprediger und einer der Verfasser ihrer Leichenpredigten, Conrad Barthels, von 1634 bis 1637 Propst und Superintendent in Klöden bei den Kannes war, ehe er von 1637 bis 1646 am Lichtenburger Witwenhof wirkte. Sein Schwiegervater war der Maler Lucas Cranach (IV), der bis zu seinem Tod 1645 in Wittenberg die Cranach-Werkstatt weiterführte. ${ }^{30}$ Den Kannes kann so eine enge Bindung an das kursächsische Haus,

24 Vgl. Landeshauptarchiv Schwerin (im Folgenden: LHA Schwerin), 2.12-1/24, verschiedene Angelegenheiten des Herzogshauses, Nr. 4, Tagebücher von Herzog Adolf Friedrich I. Eintrag vom 4. Juni 1629. Der Herzog hatte nach einer Jagd Bernhard Ludolph von Kanne auf Klöden besucht und ist vermutlich bis zum 8. Juni geblieben. Vgl. dazu auch Dirk SCHLeInerT, Anna Maria von Mecklenburg (1627-1669) und August von Sachsen (1614-1680) und die Begründung des Hauses Sachsen-Weißenfels. Dynastische Beziehungen zwischen Mecklenburg und Kursachsen im 17. Jahrhundert, in: Mecklenburgische Jahrbücher 123 (2008), S. 123-157.

25 Vgl. Calov, Verae Nobilitatis Insignia (wie Anm. 14).

26 Vgl. ebd.

27 Vgl. Schleinert, Anna Maria (wie Anm. 24), S. 129.

28 Vgl. HStA Dresden, 10024 Geheimes Archiv, Loc. 8221/3, Hoff Diarium, gehalten zu Halle bey der Geburth und Tauff Prinzeßin Sophien, Herzogin zu Sachßen de Anno 1654. Darin wird Elisabeth von Kanne als anwesende Taufpatin erwähnt. Zur Hochzeit zwischen Anna und August vgl. Essegern, Fürstinnen am kursächsischen Hof (wie Anm. 2), S. 381 f.; und SChleinert, Anna Maria (wie Anm. 24).

29 Vgl. Geier, Himlische Zusammenkunft (wie Anm. 16); sowie auch ArnswaldT, Geschichte (wie Anm. 14), S. 353 f. Nach seiner Rückkehr aus Dänemark nahm er am kursächsischen Hof in Dresden eine Karriere als Oberhofmarschall, Geheimer Rat, Oberkämmerer, Oberst und Amtshauptmann für Gräfenhainichen, Schlieben, Schweinitz und Seyda sowie Obersteuereinnehmer. Er starb 1677 ohne männliche Nachkommen.

30 Vgl. Werner Schade, Die Malerfamilie Cranach, Dresden 21977, S. 108; NiKOlaus MÜLLER, Die Funde in den Turmknäufen der Stadtkirche zu Wittenberg, Magdeburg 1912, S. 54-58; sowie die Leichenpredigt für Conrad Barthels: JACOB WELler, Frommer Lehrer herrliche Grabschrifft ... angestellet bey der ... Leichen-Begaengnueß ... M. Conradi Barthels ..., Dresden 1662 (VD17 39:107829Q und VD17 125:034288H). Zu untersuchen gilt, 
aber auch an die mit Mecklenburg verwandte Sekundogenitur Sachsen-Weißenfels und damit zu Hedwigs mecklenburgischen Verwandten bescheinigt werden.

Ein weiteres Ereignis dürfte sich ebenfalls prägend auf die Erinnerungskultur der Familie von Kanne an die verstorbene kursächsische Witwe Hedwig ausgewirkt haben. 1666 heiratete die dänische Prinzessin Anna Sophia (1647-1717) den sächsischen Prinzen und späteren Kurfürsten Johann Georg III. (1647-1691). Als Leibgedinge erhielt sie, wie bereits ihre Großtante Hedwig, das Schloss Lichtenburg mit den Ämtern Schlieben, Schweinitz und Seyda. Ab 1687 residierte in Lichtenburg ihre Schwester Wilhelmine Ernestine von Dänemark (1650-1706), die verwitwete Kurfürstin von der Pfalz. Anna Sophia selbst trat 1691 nach dem Tod ihres Mannes das Wittum an. ${ }^{31}$ Es ist davon auszugehen, dass auch die Nachkommen des Bernhard Ludolph von Kanne am Lichtenburger Witwenhof der beiden dänischen Schwestern bekannt waren, da sie als Rittergutsbesitzer den Witwen Ritterdienste zu leisten hatten. Vielleicht wurden die Töchter sogar von den beiden fürstlichen Witwen erzogen oder als Hofdamen aufgenommen. ${ }^{32}$

ob dieser Lucas Cranach (IV) vielleicht Urheber der heute noch in Lichtenburg nachweisbaren Wandmalereien ist, welche aus der ersten Hälfte des 17. Jahrhunderts stammen. Vgl. dazu die 2012 an der Hochschule für Bildende Künste in Dresden verteidigte Diplomarbeit von CHRistine PiePer, Die Wandmalereien des südlichsten Frauengemachs (Raum A) im ersten Obergeschoss des Ostflügels in Schloss Lichtenburg.

31 Vgl. UtE EsSEgern, Kein Spielraum für Frauen? Hochzeitsverhandlungen und Heiratsverträge zwischen Sachsen und Dänemark in der Zeit von 1548 bis 1709, in: Kappel/ Brink, Mit Fortuna übers Meer (wie Anm. 2), S. 55-61, vor allem S. 58 f. Zu Anna Sophia vgl. auch Claudia BRINK, Anna Sophia. „Fortuna auf dem Glücks-Schiff“, in: ebd., S. 207211, besonders S. 210 f. Kaum untersucht ist bisher die Rolle des Pietismus am Lichtenburger Hof der dänischen Schwestern. Zwei neuere Aufsätze widmen sich jedoch dem Thema. Vgl. Juliane JACOBI, Geförderte Lebensläufe? Werdegänge Hallescher Waisenkinder (1695-1730), in: Juliane Jacobi/Jean-Luc Le Cain/Hans-Ulrich Musolff (Hg.), Vormoderne Bildungsgänge in der Frühen Neuzeit, Köln 2010, S. 115-130; sowie LUCINDA MARTIN, Öffentlichkeit und Anonymität von Frauen im (Radikalen) Pietismus. Die Spendentätigkeit adliger Patroninnen, in: Wolfgang Breul/Marcus Meier/Lothar Vogel (Hg.), Der radikale Pietismus: Perspektiven der Forschung, Göttingen 2010, S. 385-401. Anna Sophia hatte seit ihrer Dresdner Zeit ein enges Verhältnis zu dem Theologen und einem der bekanntesten Vertreter des Pietismus Philipp Jakob Spener (1635-1705), der auch nach seinem Weggang von Dresden nach Berlin jedes Jahr nach Lichtenburg kam und dort predigte. Die beiden Witwen Anna Sophia und Wilhelmine Ernestine nahmen in Lichtenburg Waisenkinder auf, welche sie zur Erziehung nach Halle zu August Hermann Francke (1663-1727) schickten, der 1695 in Halle eine Schule eröffnete, aus der 1698 die Franckeschen Stiftungen entstanden. Zudem sind nach Lucinda Martin im Archiv der Franckeschen Stiftungen Akten überliefert, welche die Stiftungstätigkeit der beiden Fürstinnen belegen. Denkbar ist, dass im Umfeld des Lichtenburger Hofes auch die Kinder Raban von Kannes mit pietistischem Gedankengut in Berührung kamen. Alternativ ist aber auch zu überlegen, ob die Kannes durch ihre Nähe zum Hof des Herzogs August von Sachsen-Weißenfels und seiner Frau Anna Maria von Mecklenburg Kontakt zu Francke und zum Pietismus hatten. Elisabeth von Kanne, die Mutter Rabans, war eine Vertraute Anna Marias. Allerdings ist Anna Maria schon 1669 verstorben. Vgl. Anm. 24, 27 und 28.

32 Leider sind keine Hofbücher überliefert, die dies bestätigen könnten. Auch die Kirchenbücher der Schlosskirche von Lichtenburg, überliefert im Pfarrarchiv Prettin, geben keine Hinweise darauf, da dort nur wenige Adlige namentlich erwähnt werden. 


\section{Hedwig als Kirchenpatronin}

Hedwig hatte, wie bereits erwähnt, im Sommer 1611 das Renaissanceschloss Lichtenburg als Witwensitz übernommen. ${ }^{33}$ Die Wittumsämter wurden ihr mit allen wesentlichen Nutzungen, Einnahmen und Rechten eingeräumt, wie sie zuvor der sächsische Kurfürst besessen hatte. Dazu gehörte auch das Patronatsrecht über die in den Wittumsämtern vorhandenen Kirchen. ${ }^{34}$ Hedwig konnte zwar keine Kirchenvisitationen durchführen, erließ aber für ihre Schlosskirche eine eigene Kirchenordnung ${ }^{35}$ und hatte Mitspracherecht bei der Besetzung von Pfarrstellen. Schon kurz nach der Wittumsübernahme setzte eine rege Bautätigkeit ein, von der vor allem die Pfarrkirchen profitierten. Hedwig ließ die Lichtenburger Schlosskirche sanieren, stiftete einen neuen Altar und übergab den alten der Prettiner Stadtkirche nebst einer neuen Kanzel, neuen Fenstern, einem Taufstein und dem Ornat. Auch die Kirchen in Schweinitz und Seyda wurden von Hedwig beschenkt. ${ }^{36}$ Zwischen 1616 und 1632 ließ Hedwig die in hölzerner Fachwerkbauweise errichtete Kirche St. Peter und Paul in Labrun neu bauen. ${ }^{37}$ Der Stifterhinweis Hedwigs ist hier in der Decke eingelassen. ${ }^{38}$ Der heutige Altar in Labrun verfügt über eine Einfassung, welche ähnlich wie der Genthaer Altar mit der Buchstabenkombination $\mathrm{C}$ und $\mathrm{H}$ spielt: den Anfangsbuchstaben für Churfürstin/Hedwig oder Christian/Hedwig. ${ }^{39} 1620$ ließ Hedwig eine neue Kirche in Hohndorf und 1623 eine Kirche im Jagdschloss Glücksburg bauen. ${ }^{40}$ Für Glücksburg stiftete sie einen Altar und ließ sich darin als Stifterin verewigen. Heute ist dieses Bild allerdings nur noch als Beschreibung aus der Zeit um 1800 überliefert: In der Mitte des Altars ist eine gemablte Tafel, darauf ein Crucifix stebet, an dessen Stammbaum liegt die Churfürstin auf denen Knien mit fliegenden Haaren und erbobenen Angesicht, umfasset das Crucifix und drücket es mit einer holdseeligen Mine an ibre Brust: An dem

33 Vgl. Essegern, Fürstinnen am kursächsischen Hof (wie Anm. 2), S. 73-76.

34 Vgl. ebd, S. 63-66. Nur die wichtigsten landesherrlichen Rechte waren ausgeschlossen.

35 Vgl. BARTHELs, Christlicher Leich-Sermon (wie Anm. 3), Bl. 58 f. Conrad Barthels erwähnt in der Leichenpredigt, Hedwig habe für ihre Schlosskirche eine eigene Kirchenordnung erlassen. Fürsten und Herren, welche diese gesehen, wollten Abschriften für ihre eigenen Hofkapellen haben.

36 Vgl. Joseph Michael, Hohendorffische Kirchweih: Eine Christliche Predigt/bey der Bestatigung der newen Kirchen zu Hohendorff ...; Geschehen den 15. Octobris ... Anno 1620, Wittenberg 1621 (VD 17 3:634268H ), S. 9; sowie BARTHELS, Christlicher Leich-Sermon (wie Anm. 3).

37 Vgl. Barthels, Christlicher Leich-Sermon (wie Anm. 3), S. 42. Hier wird explizit erwähnt, Hedwig habe vier Kirchen in Gentha, Glücksburg, Labrun und Hohndorf von Grund auf neu bauen und etliche andere Kirchen sanieren lassen. Erwähnt werden auch Stiftungen von Altären, Kanzeln, Taufsteinen, Kelchen und priesterlichen Ornaten, wie z. B. in Prettin, Seyda und Schlieben.

38 Vgl. www.labrun-kirche.de/historie (Zugriff 27. Dezember 2011).

39 Vgl. Kappel/Brink, Mit Fortuna übers Meer (wie Anm. 2), vor allem S. 156 f. Hedwig selbst verwendete oft Zahlenrebusse und Monogramme in der Kombination 3/8 und $\mathrm{C} / \mathrm{H}$, ohne jedoch die Auflösung zu geben.

40 Vgl. für die Kirchenstiftung in Hohndorf die Kirchweihpredigt: MichaEL, Hohendorffische Kirchweih (wie Anm. 36); sowie für Glücksburg: JOSEPH MicHAEL, Glücksburgische Kirchweih: Eine Christliche Predigt/ bey der Inauguration und bestetigung der newen Kirchen zur Glücksburgk/ Welche von der ... Frawen Hedwig/ Gebornen aus Königlichem Stamme Dennemarck/ Hertzogin zu Sachsen ... Churfürstin ... Widwen/ erbawet/ unnd ... eingeweihet worden, Wittenberg 1623 (VD 17 14:015130G). Vgl. auch BARTHELS, Christlicher Leich-Sermon (wie Anm. 3). 
aufgeschlagenen Schlitz ibres Kleides stehet neben dem Fuße diese Schrifft: Von Gottes Gnaden Hedewig, gebobren aus Königl. Stam[m] zu Dennemarck, Churfürstin und Hertzogin zu Sachsen, Jülich, Cleve und Berg, Witwe. Zu beyden Seiten dieses Crucifixes stehen Maria und Johannes gemablet, die sie am Creutz Christi sollen gestanden haben, und wie sie der Künstler der es gemablet, zu Rom gesehen. Oben am Altare stehet HC [Ligatur], so Churfürstin Hedewig heißen soll, und in der Fuge die Jabreszabl 1622. ${ }^{41}$

Dass viele der Wittumskirchen und auch deren Pfarrer von ihr unterstützt wurden, ist hinlänglich in Hedwigs Leichenpredigten überliefert. ${ }^{42}$ Bis heute überdauert hat auch Hedwigs Abendmahlstiftung aus dem Jahr 1624, in welcher sie zahlreiche Pfarrkirchen ihres Wittums beschenkte und Gelder für Hilfsbedürftige bereitstellte. ${ }^{43}$ Sie unterstützte nicht nur die Pfarrer ihres Wittums. Auch über die Landesgrenzen hinaus war ihr Streben um die Bewahrung des Lutherischen Glaubensbekenntnisses bekannt. 1633 widmete ihr der Jenaer Theologieprofessor Johann(es) Gerhard sein Buch „Scholae Pietatis Libri V“.44

41 Vgl. Stefan Pratsch, Beschreibendes Inventar von Dorfkirchen des Altkreises Jüterbog-Lukenwalde wiederentdeckt, in: Brandenburgische Denkmalpflege 11 (2002), H. 1, S. 50 f. Der Autor befasst sich mit einer im Heimatmuseum Jüterbog aufbewahrten handschriftlichen Chronik, die unter Federführung des Bürgermeisters Carl Gottlieb Ettmüller um 1800 entstanden ist und im Anhang eine Beschreibung von 22 Dorfkirchen enthält. Dr. Mario Titze vom Landesamt für Denkmalpflege und Archäologie SachsenAnhalt stellte mir freundlicherweise Auszüge einer von Pratsch gefertigten Abschrift zur Verfügung, aus der auch das Zitat (S. 292 f.) übernommen wurde. Die Kirche von Glücksburg ist auf den Seiten 291 bis 294 beschrieben. Interessant ist, dass der Chronist selbstverständlich davon ausgeht, dass $3 / 8, \mathrm{C} / \mathrm{H}$ und $\mathrm{H} / \mathrm{C}$ für Churfürstin/Hedwig stehen. $\mathrm{Ob}$ tatsächlich im Original auf S. 293 die Ligatur HC verwendet wurde, oder ob es sich um einen Schreibfehler des Chronisten handelt, muss offen bleiben. Bisher ist für Hedwig vor allem die Kombination C/H nachweisbar, vgl. Anm. 39. Die für das Glücksburger Gemälde beschriebene Form der Stifterdarstellung ist durchaus typisch. So zeigt ein 1577/78 von Cornelius Krommeny für die Rühner Klosterkirche geschaffener Altar ebenfalls das Abendmahl, das herzogliche Stifterpaar Ulrich von Mecklenburg (1527-1603) und Elisabeth von Dänemark (um 1523/24-1586), Hedwigs Großeltern, daneben knieend und betend. Das Kloster hatte Elisabeth 1575 von Ulrich geschenkt bekommen und sich um eine Neubelebung als adliges Stift bemüht. Vgl. Carsten NeumanN, Die Renaissancekunst am Hofe Herzog Ulrichs zu Mecklenburg, Kiel 2009, S. 177 sowie S. 196-202.

42 Vgl. Essegern, Fürstinnen am kursächsischen Hof (wie Anm. 2), S. 201-204. Vgl. auch Hedwigs Leichenpredigt: MATTHIAS HOË vON HOËNEGG, Christliche Leichpredigt Alß der Durchlauchtigsten/ Hochgebornen Fürstin/ und Frawen/ Frawen Hedewig ... / Geborne[n] auß Königlichem Stam[m] zu Dennemarck/ Hertzogin zu Sachsen/ Gülich/ Cleve und Berg/ Churfürstin ... Wittib ..., Leipzig 1643 (VD 17 39:109728L). Vgl. auch BARTHELS, Christlicher Leich-Sermon (wie Anm. 3). Überliefert sind weitere Leichenpredigten, doch zählen diese beiden Autoren zu Hedwigs engeren Vertrauten. Neben den bereits erwähnten Kirchen verfügt heute die ebenfalls in Fachwerkbauweise errichtete Kirche von Kremitz bei Annaburg über einen Taufstein mit den Initialen Hedwigs. So ist anzunehmen, dass sie diesen stiftete.

43 Vgl. EsSEGERN, Fürstinnen am kursächsischen Hof (wie Anm. 2), S. 204-210 und ebd. Abschrift der Stiftung auf S. 447-449.

44 Vgl. JohanN Gerhard, Scholae Pietatis Libri V., Jena 1633 (VD 17 23:245909P). Gerhard war ein bekannter lutherischer Theologe und einer der bedeutendsten Vertreter der lutherischen Orthodoxie in jener Zeit, vgl. Franz LAU, Johann Gerhard, in Neue Deutsche Biographie 6 (1964), S. 281, Onlinefassung: http://www.deutsche-biographie.de/ sfz20587.html (Zugriff 29. Dezember 2011). Auch andere Pfarrer unterstützte Hedwig, wie z. B. den 1617 vom Katholizismus zum Luthertum übergetretenen Paul Helmreich. Vgl. Paul Helmreich, Hertzliche/ Christliche Widerruffs-Predigte/ Der Bäbstischen Irr- 
Unstrittig ist, dass Hedwigs Witwenzeit von einer für Witwen typischen, intensiven und zunehmenden Frömmigkeit geprägt war. ${ }^{45}$ Sie trauerte lange um ihren verstorbenen Ehemann Christian II. von Sachsen. ${ }^{46}$ In diesen Kontext ist auch ihr Engagement für die Pfarrer und Kirchen des Wittums einzuordnen. Aus Hedwigs Sicht mag dies nicht ungewöhnlich oder außergewöhnlich gewesen sein. Schließlich hatte sie aufgrund ihrer guten finanziellen Absicherung und späteren Erbschaften die entsprechenden finanziellen Möglichkeiten. ${ }^{47}$ Die Menschen in der Region sahen dies jedoch anders. Mit Hedwig lebte erstmals eine hochadlige Person über viele Jahre direkt neben ihnen, herrschte über sie und sorgte sich um sie. Durch ihr weitreichendes persönliches Netzwerk schaffte es Hedwig immer wieder, ihr Wittum vor größeren Zerstörungen und Plünderungen zu bewahren. Sie verhandelte mit den Gegnern Kursachsens, erhielt mehrfach Schutzbriefe sowohl von Schweden als auch von kaiserlichen Truppen. ${ }^{48}$ Diese Erinnerung lebte lange in den Menschen der Region fort und wurde insbesondere in den von Hedwig unterstützten Kirchen bewahrt. Und es ist sicherlich auch kein Zufall, dass gerade Hedwigs Abendmahlstiftung die Jahrhunderte bis heute überdauert hat. ${ }^{49}$ Hedwig galt in der regionalen Erinnerungskultur als echte Landesherrin, als Bewahrerin des Lutherischen Glaubens, als Erbauerin von Kirchen, als Vorbild, vielleicht sogar als ,Jüngerin Jesu' ${ }^{50}$ Sie selbst wollte immer ein Teil der christlichen Gemeinde sein, eine Dienerin Gottes. ${ }^{51}$

thumb ..., Wittenberg 1622 (VD17 12:206565S). Zur Biografie Helmreichs vgl. JAKOB FrANCK, Paul Helmreich, in: Allgemeine Deutsche Biographie 11 (1880), S. 707 f., Onlinefassung: http://www.deutsche-biographie.de/sfz29596.html (Zugriff 29. Dezember 2011).

45 Zur Witwenschaft in der Frühen Neuzeit vgl. u. a. SCHATTKOwsKY, Witwenschaft (wie Anm. 2); sowie BritTA-Juliane Kruse, Witwen. Kulturgeschichte eines Standes in Spätmittelalter und Früher Neuzeit, Berlin 2007, dort auch weitere Literaturhinweise.

46 Vgl. HoËNEgG, Christliche Leichpredigt (wie Anm. 42). In Hedwigs Nachlass befand sich ein lebensgroßes Leichenbild Christians II. von Sachsen, vgl. HStA Dresden, 10024 Geheimes Archiv, Loc. 10553/1, Lichtenburgische Wittumssachen, 1611 ff., Bl. 96132, Inventar Schloss Lichtenburg, 1642.

47 Vgl. Essegern, Fürstinnen am kursächsischen Hof (wie Anm. 2), S. 152-163, besonders S. 154.

48 Vgl. ebd., z. B. S. 176-182.

49 Zur Abendmahlstiftung vgl. Anm. 43.

$50 \mathrm{Ob}$ Hedwig tatsächlich zeitgenössisch als Jüngerin gesehen wurde, lässt sich leider nicht mehr feststellen. Allerdings gibt es Vergleichsbeispiele. Zwei sind im Umfeld des Pietismus angesiedelt. Die zweite Frau von Nikolaus Ludwig Zinzendorf (1700-1760), Anna Nitschmann, wurde schon zu deren Lebzeiten um 1757 als „Jüngerin“ bezeichnet. Vgl. LuCINDA MARTIN, Anna Nitschmann (1715-1760): Priesterin, Generalältestin, Jüngerin der weltweiten Brüdergemeine; http://halle.academia.edu/LucindaMartin/ Papers/197323 (Zugriff 4. März 2012). Auch Gräfin Aemilie Juliane von SchwarzburgRudolstadt (1637-1706) wird als solche bezeichnet. Vgl. dazu Anm. 56. In zeitgenössischen Leichenpredigten finden sich auch Vergleiche mit den biblischen Jüngerinnen Tabea und Maria Salome. Cornelia Moore hat mich freundlicherweise auf die folgende Leichenpredigt hingewiesen: MARTIN TITIUS, Leichpredigt: Von der frommen Jüngerin Tabea/ welche zu Joppen gestorben/ und von Petro wieder aufferwecket worden/ aus den Apostolischen Geschichten am 9.: Bey der Adelichen Sepultur Der ... Jungfrawen Elisabeth/ gebornen von Kißleben/ Welche am verschienem newen Jahrstage ... zu Quedlinburg selig entschlaffen/ und den 15. Ianuarii, dieses lauffenden Jahrs 1624. in der Pfarrkirchen S. Benedicti darselbsten beygesetzet worden, Halberstadt 1624 (VD 17 1:029218F). Im VD 17 lassen sich unter dem Stichwort „Jüngerin“ weitere Beispiele finden.

51 Vgl. Hedwigs Leichenpredigt: BARTHELs, Christlicher Leich-Sermon (wie Anm. 3), z. B. Hedwig als Landesmutter (S. 12, 16, 86), ihr gelebter Glauben (S. 19), ihr Einsatz für die Untertanen (S. 26), als Glied der Gemeinde (S. 67). 


\section{Schlussbemerkung}

Aufgabe der Erinnerungskultur (Memoria) ist es, die Vergangenheit lebendig zu halten und Botschaften zu vermitteln. Historische Ereignisse werden dabei nicht zwingend objektiv dargestellt. Aktuelle Perspektiven, aber auch subjektive Wahrnehmungen verändern den Blick auf die Vergangenheit. So ist die Memoria vielen Einflüssen ausgesetzt. Dies gilt auch für die fürstliche Memoria, die oft zugleich auch politisch geprägt ist. ${ }^{52}$

Die zeitgenössische Erinnerungskultur an verstorbene Fürstinnen, häufig überliefert in Form von Leichenpredigten, verfolgte zumeist ein wichtiges Ziel: die Verstorbenen sollten Vorbilder für die Lebenden sein. Entsprechend lag der Schwerpunkt insbesondere auf der Darstellung der Tugenden. Die Leichenpredigten für die kursächsische Witwe Hedwig zum Beispiel würdigten die Fürstin vor allem als gebildete, gottesfürchtige und mildtätige Frau, welche sich für ihre Untertanen einsetzte, sie förderte und unterstütze und fest zum Lutherischen Glaubensbekenntnis hielt. ${ }^{53}$

Neben den Leichenpredigten sind auch die Grabdenkmäler eine Form der Erinnerungskultur. Diese müssen sich nicht zwangsläufig an dem Ort befinden, wo eine Person bestattet ist. Das Altarbild der Genthaer Kirche mit dem eingearbeiteten dänischen Wappen sowie den Symbolen 3/8 und C/H lässt vermuten, dass der 1695 entstandene Altar durchaus ein (verstecktes) Epitaph für die 1641 verstorbene Hedwig von Dänemark sein könnte. ${ }^{54}$ Ist dies der Fall, so liegt die Zuordnung der eindeutig als Frau identifizierbaren Person an der Seite der elf Jünger zu Hedwig im Bereich des Möglichen.

Hedwigs Wirken als kursächsische Witwe in ihren Wittumsämtern allgemein und als Kirchenpatronin speziell untermauert diese These: Johanna Elisabeth von Kanne ließ den Altar 1695 aus heute nicht mehr eindeutig rekonstruierbaren Gründen der Frömmigkeit heraus schaffen. Sie setzte damit Hedwig von Dänemark ein bleibendes Denkmal und würdigte deren Leistungen für die Kirche von Gentha und vielleicht sogar darüber hinaus.

$\mathrm{Ob}$ nun Hedwig dargestellt ist oder nicht - auch kunst- und kirchenhistorisch bietet der Altar Platz für weitere Forschungen. So ist zu überlegen, inwieweit pietistische Anschauungen bei der Stiftung und Gestaltung des Altars eine Rolle gespielt haben könnten. Wie beschrieben, konnte die Familie von Kanne über den Lichtenburger Witwenhof der beiden dänischen Schwestern Wilhelmine Ernestine und Anna Sophia auch

52 An der Universität Gießen läuft beispielsweise aktuell ein Forschungsprojekt zur fürstlichen Memoria: http://www.uni-giessen.de/erinnerungskulturen/home/projekt bereich-8.html (Zugriff 24. Juni 2012). Darüber hinaus war dies für das Mittelalter und die Frühe Neuzeit schon mehrfach Gegenstand von Forschungen. Vgl. z. B. GERD Althoff, Adels- und Königsfamilien im Spiegel ihrer Memorialüberlieferung. Studien zum Totengedenken der Billunger und Ottonen, München 1984; ARNOLD ANGENENDT, Theologie und Liturgie der mittelalterlichen Toten-Memoria, in: Karl Schmid/Joachim Wollasch (Hg.), Memoria. Der geschichtliche Zeugniswert des liturgischen Gedenkens im Mittelalter (Münstersche Mittelalter-Schriften 48), München 1984, S. 79-199; PhiLipPE ARIÈs, Geschichte des Todes, München 91999; Mark Hengerer (Hg.), Macht und Memoria. Begräbniskultur europäischer Oberschichten in der Frühen Neuzeit, Köln u. a. 2005; ANDREA BARESEL-BRAND, Grabdenkmäler nordeuropäischer Fürstenhäuser im Zeitalter der Renaissance 1550-1650, Kiel 2007.

53 Vgl. Essegern, Fürstinnen am kursächsischen Hof (wie Anm. 2), S. 198-204. Vgl. auch Kapitel III dieses Beitrags.

54 Diese Möglichkeit zieht Dr. Frank Schmidt, Leiter des Kunstdienstes der Evangelisch-Lutherischen Landeskirche Sachsen, als eine Variante in Betracht. 
mit pietistischem Gedankengut in Berührung gekommen sein. Der Theologe Philipp Jacob Spener, ein enger Vertrauter Anna Sophias und regelmäßig in Lichtenburg anwesend, vertrat in seinem 1689 erschienenen Buch „Kurtze Catechismus-Predigten“ die Auffassung einer spirituellen Gleichheit von Mann und Frau. ${ }^{55}$ Interessant ist, dass das Titelbild einer 1692 von Spener herausgegebenen Druckschrift ebenfalls das Heilige Abendmahl zeigt. Wie im Altarbild der Genthaer Kirche ist auch hier eine Frau an der Seite der Apostel abgebildet. ${ }^{56}$

55 Vgl. Philipp Jacob Spener, Kurtze Catechismus-Predigten: Darinnen Die fünff Haupt-Stück/ auß dem Catechismo/ Und die Hauß-Taffel/ Samt Den Fest-Materien/ Einfältig erkläret werden, Frankfurt am Main 1689 (VD17 23:272809E). Vgl. dazu auch ULRIKE GleIXner, Pietismus und Bürgertum. Eine historische Anthropologie der Frömmigkeit, Göttingen 2005, S. 212. Speners Buch ist interessanterweise der sächsischen Kurfürstin Anna Sophia von Dänemark gewidmet. Zu Anna Sophias Wirken in Lichtenburg vgl. Anm. 31.

56 Vgl. Johannes TAuler, Deß hocherleuchten und weitberühmten Lehrers D. Joh. Tauleri Predigten Auff alle Sonn- und Feyertage durchs gantze Jahr: ... , Auch ist dieser neuen Edition noch bey gefügt eine Vorrede Herrn D. Philipp Speners, Frankfurt am Main 1692 (VD 17 23:249773V). Den Hinweis verdanke ich Judith Aikin, welche sich mit dem Leben und Wirken der Gräfin Aemilie Juliane von Schwarzburg-Rudolstadt (1637-1706) beschäftigt. Ihrer Information folgend war dieses Gemälde Teil des Traueraltars für die verstorbene Aemilie Juliane. Das Original-Gemälde des Altars von Seivert Lammers gilt als verschollen, ein Kupferstich des Altars von Johann Christian Marchand ist nach Auskunft von Frau Aikin in der folgenden Leichenpredigt enthalten: Schwartzburgisches Denkmal einer Christ-Gräflichen Lammes-Freundin, Rudolstadt 1707. Zudem wird nach Auskunft von Frau Aikin in den Leichenpredigten zweimal Bezug auf Aemilie Julianes Darstellung als der zwölfte Jünger (und einzige Jüngerin) genommen. Durch die Mitwirkung Speners an dem 1692 erschienenen Druck wird zugleich ein pietistischer Einfluss sichtbar. Vgl. auch Anm. 31 (zu Spener) und Anm. 50 (zur Darstellung von Frauen als Jüngerinnen). 